\title{
A Critique of the Environmental Sustainability Index ${ }^{\text {t }}$
}

Raghbendra Jha,

Australian National University,

\author{
K.V. Bhanu Murthy, \\ University of Delhi
}

\begin{abstract}
The Environmental Sustainability Index (ESI) has been proposed by collaboration of the World Economic Forum, Geneva, Center for International Earth Science Information Network, Columbia University, and Yale Center for Environmental Law and Policy, New Haven as a measure of the overall state of the environment. This paper argues that the basic design of the ESI leaves much to be desired. It has conceptual problems in its visualization of environmental degradation and sustainability. The choice of variables as well as the statistical methodology of compiling the index is also found to be wanting. The paper then proposes an alternative methodology using Principal Components Analysis and argues that this is an improvement upon the ESI methodology. Given the likely use of aggregate environmental indexes in future environmental management, the critique advanced in this paper is of considerable significance.
\end{abstract}

All communication to:

Prof. Raghbendra Jha, Australia South Asia Research Centre, Australian National University, Canberra, ACT 0200, Australia

Fax: + 61261250443

Fax: + 61261252683

Email: r.jha@anu.edu.au

Keywords: Environmental sustainability, Principal Components Analysis

JEL Classification No. Q01, Q38, Q39

\footnotetext{
${ }^{*}$ We are grateful to the John D. and Catherine T. MacArthur Foundation for financial support and Stephanie Hancock for research assistance. Comments from participants at the 2003 Frontiers 2 Conference in Spain are gratefully acknowledged.
} 


\section{Introduction}

A central issue in the context of the environment is that of its sustainability. This presumes the development of an index that encapsulates both the current state of the environment as well as its potential to provide support for future human activity. As would be expected there is a plethora of definitions of the concept of sustainability. We have proposed that the applicability of the notion of sustainability has ultimately got to be universal and refer to the indefinite future. (Jha and Murthy (2000)).

Once the broad contours are accepted the need for a measure of sustainability arises. Obviously such a measure must be general enough to cover various dimensions of environmental degradation and potential as well as all countries in the world. Such a measure is necessary for making international and inter-temporal comparisons. This would reduce the ambiguity about the role of different countries, regions and income classes in efforts for global environmental management.

The 2002 Environmental Sustainability Index (ESI) is a significant effort in this direction. It has been developed by collaboration of the World Economic Forum, Geneva, Center for International Earth Science Information Network, Columbia University, and Yale Center for Environmental Law and Policy, New Haven and is a measure of the overall progress towards environmental sustainability developed for 142 countries. It has aroused considerable interest even at the level of the scholarly popular press $\square_{\text {The ESI is based upon }}$ a set of sixty-eight basic indicators. These are then aggregated to construct twenty core indicators (Annex I of the ESI 2002 Report). These include: air quality, water quantity, water quality, biodiversity, land, reducing air pollution, reducing water stress, reducing eco-system stress, reducing waste and consumption pressures, reducing population growth, basic human

\footnotetext{
${ }^{1}$ See The Economist, 16 March 2002
} 
sustenance, environmental health, science and technology, capacity for debate, environmental governance, private sector responsiveness, eco-efficiency, participation in international collaborative efforts, reducing greenhouse gas emissions, reducing trans-boundary environmental pressures. A number of variables are used to capture each of these variables and their effect is classified according to their coverage, recency and relevance. The process of ESI construction then aggregates the 20 core indicators into five broad indicators of sustainability. These broad indicators are: a) Environmental System; b) Reducing Environmental Stress; c) Reducing Human Vulnerability; d) Social and Institutional Capacity Component; and e) Global Stewardship. These indicators are then collapsed into a single ESI. The basic structure of the ESI index is described in Figure 1.

\section{Insert Figure 1 here}

The ESI could presumably be a tool in environmental debate and, in the future, such a measure has the potential of seriously impacting domestic and international policy analysis. Hence, it is important that there be widespread acceptance of the structure and methodology of the ESI. Surely the construction of an index is an evolving process and periodic evaluation of this methodology would be useful. It needs to be compared with other such indices. The ESI report provides a review of some of the other existing indices of sustainability.

This paper seeks to critically evaluate the structure and methodology of the ESI. There are two guiding concerns in doing so. First, a broad distinction has to be made between differing standpoints in relation to sustainability. Second, sustainability has to be studied within a causal framework.

Sustainability can be discussed as per at least three distinct standpoints:

\footnotetext{
${ }^{2}$ The ESI report compares nine indices with the ESI. See ESI 2002 Report - Table 9, P.19.
} 
a) Environmental Degradation; b) Effects of Degradation; and c) Environmental Management. Clearly the first dimension affects the second. The third must be designed so as to affect the former two. A causal and an impacted variable should not be clubbed into one grand index. However, this is precisely what the ESI does.

Our critique of the ESI methodology operates at two levels. At a philosophical level we question a) the classification of variables; b) the specification (type) of the variables; and c) the coding of variables. At an empirical level at least three methodological problems arise: a) aggregation problem; b) problem of cause and effect; and c) weighting problems.

The classification of variables raises several questions. First, it is not clear why variables like urban $\mathrm{NO}_{2}$ and $\mathrm{SO}_{2}$ concentration should be a part of the 'Environmental System' whereas $\mathrm{NO}_{2}$ or $\mathrm{SO}_{2}$ emissions per populated land area should be a part of 'Reducing Environmental Stress'. Had these variables been defined as percentage drops there would have been some justification. Only two variables signifying change have been included here: one on forest cover, and most surprisingly, 'percentage change in projected population between 2001 and 2050'. How can a future (projected) rate of growth reduce present environmental stress? Moreover, the population variable does not match with the remaining variables. The variable 'proportion of under-nourished in total population' cannot be related directly to environmental degradation. A particularly serious lapse relates to the 'code' of the variables. For instance, in the core indicator 'Basic Human Sustenance' two variables are included, viz., proportion of under-nourished in total population' and percentage of population with access to improved drinking water. The problem with the 'code' is that if the index is low it favours the former variable and if it is high it favours the latter.

An important principle in the formation of an index is that the sum total of the variable must yield an interpretation that is unidirectional, i.e., the 'code' must be the same. 
Once the index is aggregated such differences would not be known to users but would continue to have serious implications for analysis.

There is a similar problem with the broad indicator - Environmental Governance. The greater the 'percentage of area under protected status' the better, presumably, is governance. However, if the subsidy is on 'energy use' and 'commercial fishing' does it still amount to better governance?

If the intention of the ESI is to be a 'near-complete' and an 'almost-correct' index, then much more needs to be said about its coverage and correctness. For instance, under 'Environmental Governance' certain variables that have been included are either antiquated or politically incorrect. The variables that emphasize protected areas lay stress on the socalled 'fence and forget' approach but ignore recent understanding on the subject of forest management. Fundamental changes in thinking about forest management have not been reflected in this approach. In real terms, a significant (though small) part of forest management is coming under co-operative management of and by the local populations (mainly tribal). This is not only more politically correct but also more appropriate because, in large parts of the world, the thorniest problem in environmental management is the reconciliation of the interest of people and nature. This approach tries to put this reconciliation into practice. The dynamics of management have evolved to "jointmanagement', i.e., private, co-operative and government and the literature on forest management has worked out the optimal shares of the three components of management (Gjertsen and Barrett (2001)).

The broad category called 'Social and Institutional Capacity' is incomplete and, at least in parts, politically incorrect since it ignores gender issues. The greatest inequity in forest management is in respect of gender. The indicator called 'Private Sector Responsiveness' has a corporate bias. It is biased towards industry and against 
agriculture/forestry. It is also biased towards corporate governance against people's governance. There is an advanced system of management of common lands, agriculture and forests called 'Heritage Parks' (Henderson (1993)). This approach is avante garde. It envisages a private sector initiative but not necessarily through 'corporates'. The indicator is incomplete also because it does not consider the role of NGOs. There are vast tracts of countryside where the corporates cannot reach. NGOs have made inroads where there is a deadlock between the government and the 'people'.

The divide between 'Social and Institutional Capacity' and 'Global Stewardship' is artificial. For instance, the source of $\mathrm{GHG}, \mathrm{CFC}$ and $\mathrm{SO}_{2}$ export is domestic. Better domestic management by each country is the only way to curb these gases. There is no way to separately curb trans-boundary pollution while not bothering about domestic pollution. Also, it is not clear why $\mathrm{CO}_{2}$ related variables are included only in Global Stewardship and excluded from indicators for environmental stress (which apparently signifies the domestic effects of pollution as opposed to the global effects). Does it imply that $\mathrm{CO}_{2}$ is not harmful for domestic residents and adversely affects only the 'global environment' by sidestepping the local environment?

The foregoing analysis although far from being complete, makes it clear that variables included in five broad indicators need to be re-examined from the point of view of coverage, correctness, unbiasedness, and above all, uniformity of 'code'. Also it is clear that five categories are not tenable. The three broad indicators, Environmental System, Stress, and Vulnerability, need to be coalesced together and sorted into two indices: Environmental Degradation and Degradation Effect. Both these indicators need to be supplemented appropriately by drawing certain variables (on 'global environment') from 'Global Stewardship'. The remaining 'Stewardship' variables can be merged with Social and Institutional Capacity, to form an indicator called 'Environmental Management'. 
Hence, there are only three logical categories of broad indicators. Any other division is not tenable. Further, these three indicators cannot be collapsed into one index since there is a causal chain amongst the three indicators. As things stand, if a country has a high index of sustainability the implication is that it has a high degree of degradation, severe degrader effects and better management as well!

There are serious problems in respect of methodology. These are: a) inter-correlation amongst variables — cause and effect; b) use of equal weights — ignoring Principal Components Analysis (PCA) ${ }^{\text {B }}$; c) ignoring outliers — truncation; d) correlation with other variables; e) ambiguity of the index (changing the sign); and f)Relevance index (implicit weights). We now briefly discuss these problems.

\section{Inter-correlation}

There is a definite purpose of data-reduction methods in general and PCA in particular. It is a methodological advancement that has great utility in the area of developing indices. There are many real world situations where a large number of observable variables represent a single phenomenon. Very often these variables may not only be correlated but causally linked (with feedback) as well. For instance, excessive paper consumption would result in deforestation, which would cause a fall in water resources and a growth in $\mathrm{CO}_{2}$ levels, which would then cause global warming, soil degradation and denudation, which would adversely affect bio-diversity and so on. In such linkages it is not possible to separate cause and effect. PCA methodology is specifically designed to deal with such a situation.

However, one of the main reasons put forward by the ESI methodology to reject the use of PCA is that the correlation amongst indicators is low (0.05) (ESI 2002 Report, p. 47).

\footnotetext{
${ }^{3}$ For a brief overview of PCA see Appendix.
} 
The problem appears to be the level at which the correlation has been measured. At the level of the twenty Core Indicators the data has already been processed to a great extent since the extreme values have been truncated and the code problem remains because of which after aggregation of individual variables at the level of indicators the correlation may be ironedout. Moreover, an ambiguous procedure of switching the numerator has been followed for obtaining the Z-scores.

\section{Equal weights}

The use of equal weights can be criticized on several counts. First, if only three separate indices were to be formed (degradation, effects, and management) and if all 68 variables were to be apportioned by ensuring the proper code, the inter-correlations would have shown-up. Second, if the arbitrary procedures were not adopted, this trend would have been more prominent. Third, the use of PCA under such circumstance would have given different results. Fourth, the 'relevance' attached to each of the variables negates the argument that 'in our judgment there was no firm basis for applying differential weights given the current state of scientific understanding' (ESI 2002 Report, p. 47).

The second argument advanced for rejecting PCA is that 'the principal component (did not) have any sensible interpretations' (p. 47 of ESI 2002 Report). However, this might have happened because of the choice, code, grouping and treatment of variables. Second, where results are not interpretable the procedure of rotation can be used in PCA methodology - an aspect that has been ignored in the construction of the ESI.

\section{Ignoring outliers}

A serious problem with the methodology is that the outliers of the variables were trimmed. Observed values above 97.5 percentile and below 2.5 percentile were reset. A meaningful 
and attractive part of PCA methodology is that it identifies and distinguishes them from influential observation. This is very relevant for environmental analysis, given the wide diversity. Removing outliers unnecessarily irons-out the variation.

\section{Correlation with other drivers}

The ESI Main Report uses the correlation between ESI and other indicators like measures of democratic institutions, control of corruption, and civil liberties. The justification for doing so is

'recognizing that per capita income does not alone determine the ESI or its constituent indicators, it becomes important to try to identify other factors which, when combined with per capita income, help to explain the observed variation in environmental outcomes'. (ESI 2002 Report, p. 22)

Further, it is said that, 'a number of variables have significant correlation with ESI, making them plausible drivers of environmental sustainability'!

However, some of these variables are already a part of ESI and for determining the drivers of environmental sustainability a causal framework as well as the Environmental Kuznets Curve literature exist ${ }^{7}$. Such an important question cannot be decided on the basis of some ad hoc correlations.

\section{Ambiguity}

Apart from the ambiguity caused by the code of variables an ad hoc procedure was used which would have created further ambiguity. This is reflected in the following statement made in the context of calculating Z-scores.

\footnotetext{
${ }^{4}$ For an analysis of the environmental Kuznets curve in a global context see Jha and Murthy (2003).
} 
"For variables in which high observed values correspond to low values of environmental sustainability, we reversed the terms in the numerator to preserve this ordinal relationship". (ESI 2002 Report, p. 46)

\section{Relevance index}

Although the methodology avoids using differential weights, it implicitly believes in one. In Table A.1.1, in Annex 1 of the ESI Report, there is a column named 'relevance'. Here the authors of the Index have implicitly specified qualitative weights for each of the 68 variables. All these variables are grouped into 20 core indicators, which are then combined into five broad indicators. We have assigned a numerical weight from 1-7 for the qualitative weights specified. This range of weights depends on the nature of comments about relevance. The weight is 1 for low and goes up to 7 for extremely high. A weighted average of such weight has been calculated for each of the 5 broad indicators. Table 1 shows the ordering amongst them.

\section{Insert Table 1 here.}

In light of this, when ESI has an implicit weighting system, why did they not use differential weights? Secondly, ESI implies that each of these indicators may hold different levels of importance for different users. In such a situation merely continuing with the five indicators cannot be rationalized.

Hence, it can be said that ESI suffers from both conceptual as well as empirical problems. Before the index can be popularized it is necessary to thoroughly rework the entire index with the help of standard methodology like PCA instead of ad hoc procedures. More importantly, we need to develop a clearer understanding of the concept of environmental sustainability and its constituents. We proceed now to our use of this methodology.

\section{Data, Methodology and Results}


A basic criticism of the ESI methodology is that it does not use Principal Component Analysis. Their own justification is in terms of the low correlation amongst variables. QThe very nature of many of the variables is such that, many of them are closely related, if not causally related. It is quite telling that, out of forty-five correlation coefficients ((10x10) - 10 (own correlation)/2), only sixteen are not significant, at the 5\% level. The remaining variables are highly correlated and have statistically significant correlation coefficients. Thus around two thirds of the variables are correlated (See Table 2).

\section{Insert Table 2 here}

It is fairly well know that if variables are correlated then PCA is ideally suited for such a situation. This is further confirmed even in cases where there are a large number of variables. The ESI is based on 68 variables. However since

" Principal Component Analysis (PCA), is a statistical technique that linearly transforms an original (large) set of variables into a substantially smaller set of uncorrelated variables, that represents most of the information in the original set of variables" report results on PCA here.

Environmental variables are usually closely related. By working with a large number of variables, the estimate (of the ESI) is prone to the vagaries of the accumulation or compounding of reporting or measurement errors. The data on environmental variables is highly prone to such errors. The ESI document is itself replete with such allusions. While many other controversial methods have been used, PCA has been consciously avoided.

The environmental variables at the global level are also prone to have non-normal or skewed distributions. Here again PCA has an advantage. It does not need the normality assumption. While observing worldwide data the variance is likely to be very high. Here again PCA has the advantage that it does not have to explain the correlation (or covariance) amongst the largest possible ("fully

\footnotetext{
${ }^{5}$ We have tested their raw variables to confirm this (Table 2).
} 
specified") set of variables. It is very economical because it uses the least number of variables to explain the full contours (of a widely spread) phenomenon by accounting for the maximum possible variance.

It is also economical because it minimizes the effort and time while achieving similar results. It reduces the cost of data collection. This is relevant especially, if the authors of ESI want it to be a model index for emulation. It can be sustained only if it is economical. Especially, if governments of poor countries are expected to collect bulky data from their own resources, the cost of collection becomes very relevant. These governments would either be dependent on donors (rich countries or Institutions) for funds for such purposes (which may have other implications) or would `cut corners ' because of which data coverage, reliability and quality would suffer.

There are set procedures for scientifically selecting these variables from amongst many. The chosen variables are known as "principal variables". There are certain measures that can be used for judging the utility (explanatory power) of such variables. Define Total Variation Explained (TVE) = $\mathrm{n}_{\mathrm{r}}+\sum_{i \in d} R_{i, r}^{2}$ where the set $\mathrm{d}$ consists of all variables; $\mathrm{n}_{\mathrm{r}}$ is the number of retained variables, and $\mathrm{R}_{\mathrm{i}, \mathrm{r}}^{2}$ stands for the squared multiple correlation of the ith discarded variable with the $r$ retained variables obtained by regressing each of the discarded variables on the four retained variables. The number of retained variables is added because each of the retained variables explains its own variation (variance $=1$ ). The measure $\mathrm{R}_{\mathrm{i}, \mathrm{r}}^{2}$ is summed over the discarded variables because it represents the variation in the discarded variables explained by the retained variables. Now, the (TVE/Total Variation) is a measure of the explanatory power. The measure of total variation is $d \times 1=d$ (since the total variation can be $100 \%$ if all variables are included).

Another advantage with PCA is that, unlike Factor Analysis it does not have to assume any underlying hypothetical factors. Yet it is possible to have a meaningful interpretation with the help of

\footnotetext{
${ }^{6}$ See Dunteman in Lewis-Beck (1994)..

${ }^{7}$ See McAbe, (1984) and Jolliffe, (1986).
} 
select variables. It only reduces the redundancy of data. The method of rotation allows better interpretation while explaining the same amount of variance. For instance, it allows us to pick up one air quality variable out of many, one bio-diversity variable amongst many, and so on. A spectrum of variables can be represented by a few.

We reduced the number of variables using three procedures: a) some variables have a 'code' problem or are not very relevant; b).the variables can easily be sorted into "Environmental Degradation Variables", "Degradation Effect Variables " and "Environmental Management Variables". This reduces the number in each category to around fifteen. The variables are chosen according to the following five criteria: a) uniformity of code; b) high coverage; c) representativeness of each aspect of the environment; d) ease of interpretations; and e) relevance. On this basis the following ten variables were selected:

VOCKM - VOCs per populated land area.

$\mathrm{SO} 2 \mathrm{KM}$ - SO2 emissions per populated land area.

PRTMAM - Percentage of mammals threatened.

PRTBRD - Percentage of birds threatened.

NOXKM - NOx emissions per populated land area.

FERTHA - Fertilizer consumption per hectare of arable land.

COALKM - Coal consumption per populated land area.

C02PC - CO2 emissions per capita.

CO2GDP - CO2 emissions per \$ GDP.

CARSKM - Vehicles per populated land area.

We have applied Varimax Rotation Criterion (Kaiser (1958)) and have accordingly retained four variables.

i) VOCKM - representing air quality.

ii) COALKM - representing depletion of resource. 
iii) PRTMAM - representing bio-diversity

iv) CO2GDP - representing global pollution.

The explanatory power of these 4 variables is given by:

$=4+2.735=6.735 / 10$ or $67.35 \%$. (as per formula above).

The Component Scores of these variables that have been used for building the EDI (Environmental Degradation Index) are given in Table 3.

\section{Insert Table 3 here}

Finally, the EDI was constructed on the basis of component scores. The ranks were established on the basis of ascending value of EDI. This was done to make the ESI and EDI comparable. The logic is, that a low value of EDI corresponds to a more sustainable environment, which can be represented by a higher value of the ESI. This makes the code of both comparable. Then the relative ranks of the 2002ESI and our EDI were compared (See Table 4).

\section{Insert Table 4 here}

Ideally, the rank correlation should have been (+) unity. This would have endorsed that there is no flaw in the estimation of 2002ESI. However, the rank correlation coefficient was only 0.1067 and the $\mathrm{Z}$ value was only 1.2. Hence, the rank correlation was not significantly different from zero. A test using the $Z$ value confirms that the rank correlation is (statistically significantly) below +1 .

There are wide differences in the ranks of many countries giving anomalous results. For instance, Australia has a difference of (-)119 in $\operatorname{rank(ESI~minus~EDI).~This~means~that~it~is~highly~}$ sustainable and extremely degrading (both simultaneously)!! Only very few countries retain the ranks. On the other hand Guinea-Bissau is hardly degrading but almost unsustainable!! This is true of most poor countries. Most of the rich countries have extremely high vehicular traffic and pollution and are by the EDI highly degrading but are fairly sustainable by the count of their ESI.

\section{Conclusions}


This paper has argued that the basic design of the ESI leaves much to be desired. It has conceptual problems in its visualization of environmental degradation and sustainability. The choice of variables as well as the statistical methodology of compiling the index are also found to be wanting. The paper has proposed an alternative methodology using Principal Components Analysis and argued this is an improvement upon the ESI methodology. Given the likely use of aggregate environmental indexes in future environmental management, the critique advanced in this paper is of considerable significance. 


\section{Appendix}

\section{Basic Analytics of Principal Components}

This appendix discusses some basic issues in Principal Components Analysis. For a fuller treatment see Lewis-Beck (1994).

If we need to choose the essential variables and arrive at relative weights for the purpose of consolidating these variables into a single index we chose Principal Components Analysis (PCA). This is popular in the literature since it has a number of desirable properties.

Consider $p$ random variables $-\mathrm{x}_{1}, \mathrm{x}_{2}, . \mathrm{x}_{\mathrm{p}}$. such that

$$
y_{1}=a_{11} x_{1}+a_{12} x_{2}+\ldots+a_{1 p} x_{p}=\sum_{i=1}^{p} a_{1 i} x_{i}
$$

PCA is a statistical technique that linearly transforms an original set of variables into a smaller set of uncorrelated variables that represents most of the information in the $\mathrm{y}_{1}$, the first principal component, is defined such that the variance of $\mathrm{y}_{1}$ is maximized subject to the constraint that the sum of squared weights is equal to 1, i.e., $\sum_{i=1}^{p} a_{1 i}{ }^{2}=1$

If the variance of $y_{1}$ is maximized then the sum of the squared correlations with the original variables is also maximized. This is written as:

$$
\sum_{i=1}^{p} r_{y, x i}^{2}
$$

PCA finds the optimal weight vector $\left(a_{11}, a_{12}, \ldots a_{1 p}\right)$ and the associated variance of $y_{1}$ which is denoted as $\lambda_{1}$.

The second principal component $\mathrm{y}_{2}$, is

$$
\mathrm{y}_{2}=\mathrm{a}_{21} * \mathrm{x}_{1}+\mathrm{a}_{22} * \mathrm{x}_{2}+\ldots+\mathrm{a}_{2 \mathrm{p}} * \mathrm{x}_{\mathrm{p}}
$$


such that the variance of $y_{2}$ is maximized subject to the constraint that the squared weights of the second weight vector $\left(a_{21}, a_{22} \ldots a_{2 p}\right)$ is equal to one:

$$
\sum_{i=1}^{p} a^{2}{ }_{2 i}=1
$$

Here, $\mathrm{y}_{2}$ is orthogonal to $\mathrm{y}_{1}$ so that

$$
\sum_{i=1}^{p} a_{1 i} a_{2 i}=0
$$

Hence, $\mathrm{y}_{2}$ has the second largest sum of squared correlation with the original variables. As successive components are extracted the variance of the principal components gets smaller. The first two principal components have the highest possible sum of squared correlation with the original variables. Therefore,

$$
\sum_{i=1}^{p} R^{2}{ }_{x i . y 1, y 2}
$$

is maximized by extracting the first two principal components. This is a measure of the explanatory power of the components.

\section{Component Scores}

The principal components are an exact mathematical transformation of the raw variables. If the objective is a simple summary of the information contained in the raw data the use of component scores is desirable. It is possible to represent the components exactly from the combination of raw variables. The scores are obtained by combining the raw variables with weights that are proportional to their component loadings. Thus if $b_{\mathrm{ij}}$ is the component loading of the jth variable on the ith. component and $\lambda_{\mathrm{i}}$ is the associated eigenvalue then the component score is given by $b_{i j} / \lambda_{i}\left(=w_{i}\right)$. 
Division by the eigenvalue assures that the resulting index has a variance equal to 1 . In our case the component scores have been used for determining the weight of each of the raw variables in constructing a composite EDI for the ith country and, similarly, for other countries.

$E D I_{i}=\sum_{j=1}^{5} w_{j} \cdot x_{j i}$

where $\mathrm{j}=$ index of selected variables. 


\section{References}

Center for International Earth Science Information Network (CIESIN), Columbia University; International Food Policy Research Institute (IFPRI); and World Resources Institute

(WRI), Gridded Population of the World (GPW), Version 2, Palisades, NY: CIESIN,

Columbia University, 2000 (available at http://sedac.ciesin.colum-bia.edu/plue/gpw.

Consultative Group on Sustainable Development Indicators, "Dashboard of Sustainable Development Indicators," dataset dated 9 January 2002.

Dunteman, G.H. " Principal Component Analysis (PCA)", in Lewis-Beck (1994).P.158

Dixon, Frank, "Financial Markets and Corporate Environmental Results,” pp. 44-53 in

World Economic Forum, Yale Center for Environmental Law and Policy, and Center

For International Earth Science Information Network, Environmental Performance

Measurement: The Global Report 2001-2002, New York: Oxford University Press, 2002.

Esty, Daniel C. and Peter Cornelius, ed., Environmental Performance Measurement: The Global Report 2001-2002, New York: Oxford University Press, 2002.

Esty, Daniel C., and Michael E. Porter (2001), "Ranking National Environmental Regulation And Performance: A Leading Indicator of Future Competitiveness?” pp. 78-101 in World Economic Forum (WEF), The Global Competitiveness Report 2001, New York: Oxford University Press.

Flatz, Alois, "Corporate Sustainability and Financial Indexes," pp. 66-81 in Daniel C. Esty and Peter Cornelius, ed., Environmental Performance Measurement: The Global Report2001-2002, New York: Oxford University Press, 2002.

Frankel, Jeffrey, and Andrew Rose, "Is Trade Good or Bad for the Environment? Sorting out the Causality," (unpublished manuscript, 2002). 
Gjertsen, H. and C. B. Barrett (2001) “Context-Dependant Bio-diversity Conservation Management Regimes”, Working Paper Series, Social Science Research Network Library, 11 February.

Harbaugh, William, Arik Levinson and David Wilson (2000), "Reexamining the Empirical Evidence for an Environmental Kuznets Curve," National Bureau of Economic Research Working Paper No. 7711, May.

Henderson, N. (1993) "Heritage landscapes : A new Approach to the Preservation of SemiNatural Landscapes in Canada and the United States", in Turner, R.K. (Ed.) Sustainable Environmental Economics and Management, Principles and Practice. Belhaven, London.

Jha, R. and K.V. Bhanu Murthy (2000) "Sustainability - Property Rights, Behaviour and Economic Growth”, World Congress on Managing and Measuring Sustainability, Ontario, August 2000.

Jha, R. and K. V. Bhanu Murthy (2003) “An Inverse Global Environmental Kuznets Curve” forthcoming Journal of Comparative Economics.

Jolliffe, T.I. (1986) Principal Component Analysis, New York, Springer-Verlag.

Kaiser, H. F. (1958) "Varimax criterion for analytical rotation in factor analysis", Psychometrica, $187-200$

Levy, Marc A. (2001) “Corruption and the 2001 Environmental Sustainability Index,” pp. 300-302 Robin Hodess, ed., Global Corruption Report 2001, Berlin: Transparency International.

Levy, Marc A., "Measuring Nations' Environmental Sustainability,” pp. 12-23 in Daniel C. Esty, and Peter Cornelius, ed., Environmental Performance Measurement: The Global Report 2001-2002, New York: Oxford University Press, 2002. 
Lewis-Beck, M.(ed.) Factor Analysis and Related Techniques, New Delhi: Sage Toppan, 1994

McAbe, G.P. (1984) "Principal Variables", Technometrics, 26: pp. 137-144.

Parris, Thomas M. and Robert W. Kates (2001), "Characterizing a Sustainability Transition: The International Consensus," paper prepared for presentation at the Open Meeting of The Human Dimensions of Global Environmental Change Research Community, 7 October, Rio de Janeiro, Brazil.

Porter, Michael, (1991) “America’s Green Strategy,” Scientific American, August.

Prescott-Allen, Robert, The Wellbeing of Nations, Washington, DC: Island Press, 2001.

Schiller, Andrew, Signatures of Sustainability: A Framework for Interpreting Relationships Among Environmental, Social, and Economic Conditions for United States Metropolitan Areas. Dissertation, Clark University, 2001.Ann Arbor: UMI, AA13003109.

United Nations, Economic and Social Council, "Implementing Agenda 21: Report of the Secretary General,” E/CN.17/2002/PC.2/7, 20, December 2001.

World Economic Forum (WEF), The Global Competitiveness Report 2001-2002, New York: Oxford University Press, 2002.

World Economic Forum (WEF) The 2002 Environmental Sustainability Index. 
Table 1: Weight Structure for Five Broad Indicators

\begin{tabular}{|l|l|l|}
\hline Indicator & Rank & Relevance Index \\
\hline Environmental System & 1 & 5.15 \\
\hline Reducing Stress & 2 & 4.53 \\
\hline Global Stewardship & 3 & 3.61 \\
\hline Social and Institutional & 4 & 3.40 \\
\hline Capacity Component & 5 & 3.0 \\
\hline Human Vulnerability & 5 & \\
\hline
\end{tabular}


TABLE 2

\begin{tabular}{llcccccccccc}
\hline & & \multicolumn{1}{c}{ Correlation Matrix } & & & & \\
\hline & & $\mathbf{1}$ & $\mathbf{2}$ & $\mathbf{3}$ & $\mathbf{4}$ & $\mathbf{5}$ & $\mathbf{6}$ & $\mathbf{7}$ & $\mathbf{8}$ & $\mathbf{9}$ & $\mathbf{1 0}$ \\
\hline Correlation & VOCKM & 1.00 & 0.29 & -0.05 & 0.03 & 0.91 & 0.24 & 0.25 & 0.37 & 0.06 & 0.43 \\
& SO2KM & 0.29 & 1.00 & 0.08 & 0.24 & 0.36 & 0.14 & 0.61 & 0.32 & 0.17 & 0.49 \\
& PRTMAM & -0.05 & 0.08 & 1.00 & 0.50 & 0.02 & 0.27 & 0.11 & 0.03 & -0.07 & 0.15 \\
& PRTBRD & 0.03 & 0.24 & 0.50 & 1.00 & 0.04 & 0.08 & 0.13 & 0.28 & 0.16 & 0.08 \\
& NOXKM & 0.91 & 0.36 & 0.02 & 0.04 & 1.00 & 0.29 & 0.32 & 0.48 & 0.13 & 0.45 \\
& FERTHA & 0.24 & 0.14 & 0.27 & 0.08 & 0.29 & 1.00 & 0.17 & 0.29 & 0.00 & 0.45 \\
& COALKM & 0.25 & 0.61 & 0.11 & 0.13 & 0.32 & 0.17 & 1.00 & 0.42 & 0.13 & 0.72 \\
& CO2PC & 0.37 & 0.32 & 0.03 & 0.28 & 0.48 & 0.29 & 0.42 & 1.00 & 0.52 & 0.42 \\
& CO2GDP & 0.06 & 0.17 & -0.07 & 0.16 & 0.13 & 0.00 & 0.13 & 0.52 & 1.00 & 0.03 \\
Level of Significann & CARSKM & 0.43 & 0.49 & 0.15 & 0.08 & 0.45 & 0.45 & 0.72 & 0.42 & 0.03 & 1.00 \\
(1-tailed) & VOCKM & 1.00 & & & & & & & & & \\
& SO2KM & 0.00 & 1.00 & & & & & & & & \\
& PRTMAM & $\mathbf{0 . 2 9}$ & $\mathbf{0 . 1 7}$ & 1.00 & & & & & & & \\
& PRTBRD & $\mathbf{0 . 3 7}$ & 0.00 & 0.00 & 1.00 & & & & & & \\
& NOXKM & 0.00 & 0.00 & $\mathbf{0 . 4 2}$ & $\mathbf{0 . 3 0}$ & 1.00 & & & & & \\
& FERTHA & 0.00 & 0.04 & 0.00 & $\mathbf{0 . 1 6}$ & 0.00 & 1.00 & & & & \\
& COALKM & 0.00 & 0.00 & $\mathbf{0 . 0 9}$ & $\mathbf{0 . 0 6}$ & 0.00 & 0.02 & 1.00 & & & \\
& CO2PC & 0.00 & 0.00 & $\mathbf{0 . 3 5}$ & 0.00 & 0.00 & 0.00 & 0.00 & 1.00 & & \\
& CO2GDP & $\mathbf{0 . 2 3}$ & 0.02 & $\mathbf{0 . 2 1}$ & 0.03 & $\mathbf{0 . 0 7}$ & $\mathbf{0 . 5 0}$ & $\mathbf{0 . 0 6}$ & 0.00 & 1.00 & \\
& CARSKM & 0.00 & 0.00 & 0.04 & $\mathbf{0 . 1 7}$ & 0.00 & 0.00 & 0.00 & 0.00 & $\mathbf{0 . 3 6}$ & 1.00 \\
\hline
\end{tabular}

NOTE: Only sixteen correlation co-efficients (in bold print) not significant at $5 \%$ level.

All the rest are highly statistically significant. 
TABLE 3

\begin{tabular}{lrrrr}
\hline \multicolumn{5}{c}{ Component Score Coefficient Matrix } \\
\hline \multicolumn{5}{c}{ Component } \\
VOCKM & 1 & 2 & 3 & 4 \\
SO2KM & -0.135 & $\mathbf{0 . 4 7 8}$ & -0.070 & -0.014 \\
PRTMAM & 0.405 & -0.141 & -0.045 & 0.040 \\
PRTBRD & -0.050 & 0.003 & $\mathbf{0 . 5 7 7}$ & -0.130 \\
NOXKM & -0.067 & -0.075 & 0.486 & 0.214 \\
FERTHA & -0.113 & 0.454 & -0.045 & 0.031 \\
COALKM & -0.039 & 0.251 & 0.261 & -0.186 \\
CO2PC & $\mathbf{0 . 5 0 3}$ & -0.174 & -0.078 & -0.037 \\
CO2GDP & 0.000 & 0.096 & 0.039 & 0.416 \\
CARSKM & -0.074 & -0.087 & -0.050 & $\mathbf{0 . 6 4 3}$ \\
\hline
\end{tabular}

Extraction Method: Principal Component Analysis.

Rotation Method: Varimax with Kaiser Normalization.

NOTE: Component scores of retained variables in bold print. 
TABLE 4

\begin{tabular}{|c|c|c|c|}
\hline ESIRANK & EDIRANK & EDI COUNTRY & $\begin{array}{c}\text { DIFF. IN RANK } \\
\text { (ESIRANK-EDIRANK) }\end{array}$ \\
\hline 59 & 1 & $0.62458 \mathrm{MOZAMBIQUE}$ & 58 \\
\hline 75 & 2 & 1.55871 EL SALVADOR & 73 \\
\hline 127 & 3 & 2.01717 GIUNEA-BISSAU & 124 \\
\hline 52 & 4 & 2.61727 NICARAGUA & 48 \\
\hline 67 & 5 & 2.8593 GAUTEMALA & 62 \\
\hline 103 & 6 & 2.87162 GAMBIA & 97 \\
\hline 95 & 7 & 2.90059 BENIN & 88 \\
\hline 39 & 8 & 3.06554 MOLDOVA & 31 \\
\hline 24 & 9 & 3.11001 ALBANIA & 15 \\
\hline 25 & 10 & 3.13468 PARAGUAY & 15 \\
\hline 82 & 11 & 3.30512 MALAWI & 71 \\
\hline 101 & 12 & 3.50494 BURKINA FASO & 89 \\
\hline 105 & 13 & 3.59708TOGO & 92 \\
\hline 98 & 14 & 3.84096 GUINEA & 84 \\
\hline 115 & 15 & 3.89209 BURUNDI & 100 \\
\hline 46 & 16 & 4.02468 ZIMBABWE & 30 \\
\hline 47 & 17 & 4.23463 HONDURAS & 30 \\
\hline 81 & 18 & 4.3492 SENEGAL & 63 \\
\hline 9 & 19 & 4.35966 COSTA RICA & -10 \\
\hline 76 & 20 & 4.51507 UGANDA & 56 \\
\hline 10 & 21 & 4.52639 LATVIA & -11 \\
\hline 69 & 22 & 4.56842 ZAMBIA & 47 \\
\hline 65 & 23 & 4.66908 GHANA & 42 \\
\hline 6 & 24 & 4.8458 URUGUAY & -18 \\
\hline 43 & 25 & 4.99391 CENT.AFR.REP. & 18 \\
\hline 111 & 26 & 5.03658 ANGOLA & 85 \\
\hline 134 & 27 & 5.36618 SIERRA LEONE & 107 \\
\hline 123 & 28 & $5.58538 \mathrm{NIGER}$ & 95 \\
\hline 119 & 29 & 5.64527 RWANDA & 90 \\
\hline 36 & 30 & 5.66084 GABON & 6 \\
\hline 109 & 31 & 5.72327 ZAIRE & 78 \\
\hline 85 & 32 & $5.92607 \mathrm{MALI}$ & 53 \\
\hline 21 & 33 & 5.95842 BOLIVIA & -12 \\
\hline 93 & 34 & 5.96559 CAMEROON & 59 \\
\hline 40 & 35 & 5.98248 CONGO & 5 \\
\hline 121 & 36 & 6.00767 TRIN. \& TOBAGO & 85 \\
\hline 108 & 37 & 6.03453 IVORY COAST & 71 \\
\hline 27 & 38 & 6.04522 LITHUANIA & -11 \\
\hline 17 & 39 & 6.1389 PANAMA & -22 \\
\hline 49 & 40 & 6.15244 BYELARUS & 9 \\
\hline 102 & 41 & 6.16058 SUDAN & 61 \\
\hline 130 & 42 & 6.2086 LIBERIA & 88 \\
\hline 56 & 43 & 6.24054 KYRGYZSTAN & 13 \\
\hline 107 & 44 & 6.32885 SYRIA & 63 \\
\hline 5 & 45 & 6.49228 SWITZERLAND & -40 \\
\hline 29 & 46 & 6.62939 PERU & -17 \\
\hline
\end{tabular}




\begin{tabular}{|c|c|c|c|}
\hline 132 & 47 & 6.64947 SOMALIA & 85 \\
\hline 38 & 48 & 6.67212 ARMENIA & -10 \\
\hline 15 & 49 & 6.70431 ARGENTINA & -34 \\
\hline 1 & 50 & 7.29555 FINLAND & -49 \\
\hline 18 & 51 & 7.35067 ESTONIA & -33 \\
\hline 32 & 52 & 7.66932 COLOMBIA & -20 \\
\hline 48 & 53 & 7.67526 VENEZUELA & -5 \\
\hline 26 & 54 & 7.7244 NAMIBIA & -28 \\
\hline 96 & 55 & 7.81316 CHAD & 41 \\
\hline 142 & 56 & 8.00832 KUWAIT & 86 \\
\hline 110 & 57 & 8.07057 TAJIKISTAN & 53 \\
\hline 41 & 58 & 8.25199 ECUADOR & -17 \\
\hline 53 & 59 & 8.32665JORDAN & -6 \\
\hline 113 & 60 & 8.328 ETHIOPIA & 53 \\
\hline 112 & 61 & 8.40256 PAKISTAN & 51 \\
\hline 133 & 62 & 8.4418 NIGERIA & 71 \\
\hline 4 & 63 & 8.65471 CANADA & -59 \\
\hline 3 & 64 & 8.66775 SWEDEN & -61 \\
\hline 12 & 65 & 8.71303 CROATIA & -53 \\
\hline 80 & 66 & 8.8542 TANZANIA & 14 \\
\hline 90 & 67 & 9.0557 MYANMAR & 23 \\
\hline 7 & 68 & 9.10917 AUSTRIA & -61 \\
\hline 13 & 69 & 9.18838BOTSWANA & -56 \\
\hline 42 & 70 & 9.2829 MONGOLIA & -28 \\
\hline 11 & 71 & 9.32622 HUNGARY & -60 \\
\hline 88 & 72 & 9.3603 KHAZAKSTAN & 16 \\
\hline 61 & 73 & 9.40425 TUNISIA & -12 \\
\hline 118 & 74 & 9.45583 UZBEKISTAN & 44 \\
\hline 14 & 75 & 9.48531 SLOVAKIA & -61 \\
\hline 54 & 76 & 9.49893 THAILAND & -22 \\
\hline 138 & 77 & 9.51953 SAUDI ARABIA & 61 \\
\hline 32 & 78 & 9.64126 LAOS & -46 \\
\hline 23 & 79 & 9.77934 SLOVENIA & -56 \\
\hline 73 & 80 & 9.82109 MOROCCO & -7 \\
\hline 99 & 81 & $9.82138 \mathrm{NEPAL}$ & 18 \\
\hline 89 & 82 & 9.85971 KENYA & 7 \\
\hline 45 & 83 & 9.89014 USA & -38 \\
\hline 57 & 84 & 10.20874 BOSNIA & -27 \\
\hline 92 & 85 & 10.25236 MEXICO & 7 \\
\hline 62 & 86 & 10.36063 TURKEY & -24 \\
\hline 139 & 87 & 10.57948 IRAQ & 52 \\
\hline 106 & 88 & 10.58927 LEBANON & 18 \\
\hline 70 & 89 & 10.63378 ALGERIA & -19 \\
\hline 131 & 90 & 11.12831 TURKMENISTAN & 41 \\
\hline 126 & 91 & 11.23059 MAURITANIA & 35 \\
\hline 97 & 92 & 11.23149 CAMBODIA & 5 \\
\hline 68 & 93 & 11.2354 MALAYSIA & -25 \\
\hline 120 & 94 & 11.46368 OMAN & 26 \\
\hline 104 & 95 & 11.48112 IRAN & 9 \\
\hline 2 & 96 & 11.71628 NORWAY & -94 \\
\hline 60 & 97 & 11.77489 GREECE & -37 \\
\hline
\end{tabular}




\begin{tabular}{|c|c|c|c|}
\hline 94 & 98 & 11.82076 VIETNAM & -4 \\
\hline 31 & 99 & 11.89112 DENMARK & -68 \\
\hline 74 & 100 & 12.04668 EGYPT & -26 \\
\hline 84 & 101 & 12.06898 ITALY & -17 \\
\hline 114 & 102 & 12.28929 AZERBAIJAN & 12 \\
\hline 20 & 103 & 12.43598 BRAZIL & -83 \\
\hline 83 & 104 & 12.4496 MACEDONIA & -21 \\
\hline 30 & 105 & 12.6481BHUTAN & -75 \\
\hline 72 & 106 & 12.79747RUSSIA & -34 \\
\hline 64 & 107 & 13.00743 CZECH. REP. & -43 \\
\hline 37 & 108 & 13.50234 IRELAND & -71 \\
\hline 86 & 109 & 13.86052 BANGLADESH & -23 \\
\hline 55 & 110 & 13.89491 SRILANKA & -55 \\
\hline 33 & 111 & 14.00751 FRANCE & -78 \\
\hline 66 & 112 & 14.38907 ROMANIA & -46 \\
\hline 77 & 113 & 14.40977 SOUTH AFRICA & -36 \\
\hline 35 & 114 & 14.66261 CHILE & -79 \\
\hline 71 & 115 & 14.66431 BULGARIA & -44 \\
\hline 122 & 116 & 14.78393 JAMAICA & 6 \\
\hline 129 & 117 & $14.9677 \mathrm{CHINA}$ & 12 \\
\hline 63 & 118 & 15.08481 ISRAEL & -55 \\
\hline 141 & 119 & 15.13046 UAE & 22 \\
\hline 136 & 120 & 15.39076 UKRAINE & 16 \\
\hline 51 & 121 & 15.50105 PAPUA N.G. & -70 \\
\hline 87 & 122 & 16.94476 POLAND & -35 \\
\hline 140 & 123 & 17.25569 N. KOREA & 17 \\
\hline 28 & 124 & 17.54867 PORTUGAL & -96 \\
\hline 124 & 125 & 17.65342 LIBYA & -1 \\
\hline 50 & 126 & 17.94292 GERMANY & -76 \\
\hline 44 & 127 & 19.04128 SPAIN & -83 \\
\hline 116 & 128 & 19.18586 INDIA & -12 \\
\hline 100 & 129 & 19.26648 INDONESIA & -29 \\
\hline 34 & 130 & 19.54603 NETHERLANDS & -96 \\
\hline 117 & 131 & 19.98959 PHILLIPINES & -14 \\
\hline 78 & 132 & 20.17706 JAPAN & -54 \\
\hline 128 & 133 & 20.9927 MADAGASCAR & -5 \\
\hline 125 & 134 & 21.04391 BELGIUM & -9 \\
\hline 16 & 135 & 21.42015 AUSTRALIA & -119 \\
\hline 58 & 136 & 21.77766 CUBA & -78 \\
\hline 91 & 137 & 22.51975 UK & -46 \\
\hline 135 & 138 & 24.91617 SOUTH KOREA & -3 \\
\hline 79 & 139 & 31.12179 DOMINICAN REP. & -60 \\
\hline 8 & 140 & 35.79837 ICELAND & -132 \\
\hline 19 & 141 & 47.41392 NEW ZEALAND & -122 \\
\hline 137 & 142 & $77.26458 \mathrm{HAITI}$ & -5 \\
\hline
\end{tabular}

\section{NOTE:}

EDI ranks (based on ascending order) is given below:

Rank Corr.=

0.106789525

Stand. Err. =

0.084215192 


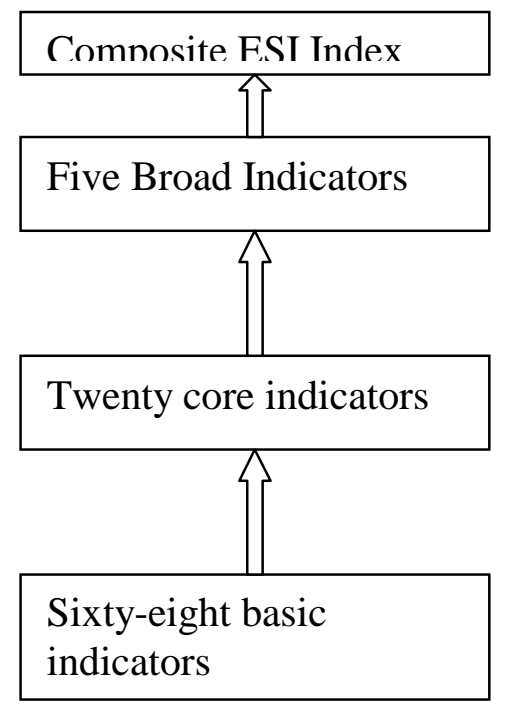

Figure 1 